УДК 330

\title{
ПУТИ ПОВЫШЕНИЯ ДОХОДОВ ОТ НЕАВИАЦИОННОЙ ДЕЯТЕЛЬНОСТИ НА РЫНКЕ ВОЗДУШНОГО ТРАНСПОРТА РФ НА ПРИМЕРЕ АЭРОПОРТА ПУЛКОВО
}

\author{
Фомина Ирина Александровна \\ к.э.н., доцент, доцент \\ Сливинский Денис Валерьевич \\ к.э.н., доцент \\ Шурыгина Мария Игоревна \\ ФГБОУ ВО «Санкт-Петербургский государственный \\ университет гражданской авиации»
}

\begin{abstract}
Аннотация: согласно докладу ACI, розничные концессии остаются крупнейшим источником неавиационных доходов для аэропортов, однако в настоящее время аэропортам стоит делать большую ставку на современные технологии при предоставлении информации и цифровизацию обслуживания. Прислушиваться к потребностям пассажиров и реагировать на то, как можно помочь сделать опыт пассажиров более легким и приятным - главная задача современного аэропорта.
\end{abstract}

Ключевые слова: аэропорт, доходы, экономика аэропортов, неавиационная деятельность аэропортов, современные технологии.

\section{WAYS TO INCREASE REVENUE FROM NON-AERONAUTICAL ACTIVITIES IN THE AIR TRANSPORT MARKET OF THE RUSSIAN FEDERATION ON THE EXAMPLE OF PULKOVO AIRPORT}

\section{Fomina Irina Aleksandrovna Slivinskii Denis Valerievich Shurygina Mariya Igorevna}

\footnotetext{
Abstract: According to the ACI report, retail concessions remain the largest source of non-aeronautical revenue for airports, but airports should now rely on advanced technology in providing information and digitalizing services. The main task for a modern airport is to listen to the needs of passengers and respond to how the airport can help make the passenger experience easier and more enjoyable.

Key words: airport, revenue, airport economics, non-aeronautical activities, modern technologies.
} 
Деятельность аэропорта делится на авиационную и неавиационную. Неавиационная деятельность аэропортов строго регламентирована документом ICAO DOC9562 «Руководство по экономике аэропортов».

По различным причинам развитие неавиационной деятельности в отечественных аэропортах началось примерно с середины 1990-х годов. Это связано, во-первых, с особенностями экономики гражданской авиации советского периода, и, во-вторых, с организационно-правовой формой существования аэропортов как структурных подразделений территориальных управлений гражданской авиации и авиаотрядов [1, с. 1].

Развитие неавиационной деятельности - один из важнейших вопросов коммерческой политики аэропорта. Доходы от неавиационной деятельности состоят из получаемых аэропортом доходов от различных коммерческих мероприятий, которые он осуществляет самостоятельно или сдавая в аренду помещения, сооружения территории, или предоставляя права деятельности (т. е. концессии), даже если на практике такие мероприятия носят авиационный характер.

Увеличение пассажирооборота ведет не просто к пропорциональному увеличению доходов от неавиационной деятельности, но и к увеличению доли этих доходов по сравнению с доходами от основной деятельности.

В то время как авиационная деятельность является основным источником доходов для большинства аэропортов, развитие неавиационной деятельности за последние 15 лет показало, что успешные аэропорты могут увеличить величину доходов от неавиационной деятельности до 50\% и более.

В аэропортах РФ доля доходов от неавиационной деятельности составляет в среднем не более $10 \%$. Тем не менее, можно выделить аэропорты, где неавиационная деятельность развивается намного успешнее, а именно аэропорты Московского авиационного узла и аэропорт Санкт-Петербурга Пулково.

Согласно докладу АCI за 2017 год розничные концессии остаются крупнейшим источником неавиационных доходов для аэропортов - 30,2\%. Концессионеры являются для аэропорта вторым по значимости заказчиком после авиакомпаний [2].

Однако в настоящее время аэропортам стоит делать большую ставку на современные технологии при предоставлении информации и цифровизацию обслуживания.

На основании он-лайн исследования компании Atmosphere Research к 2021 году рынок продаж перевозок окажется на пороге «пост-мобильного» мира, где смартфон больше не будет одним из инновационных каналов продаж, а будет основным (рис. 1). 


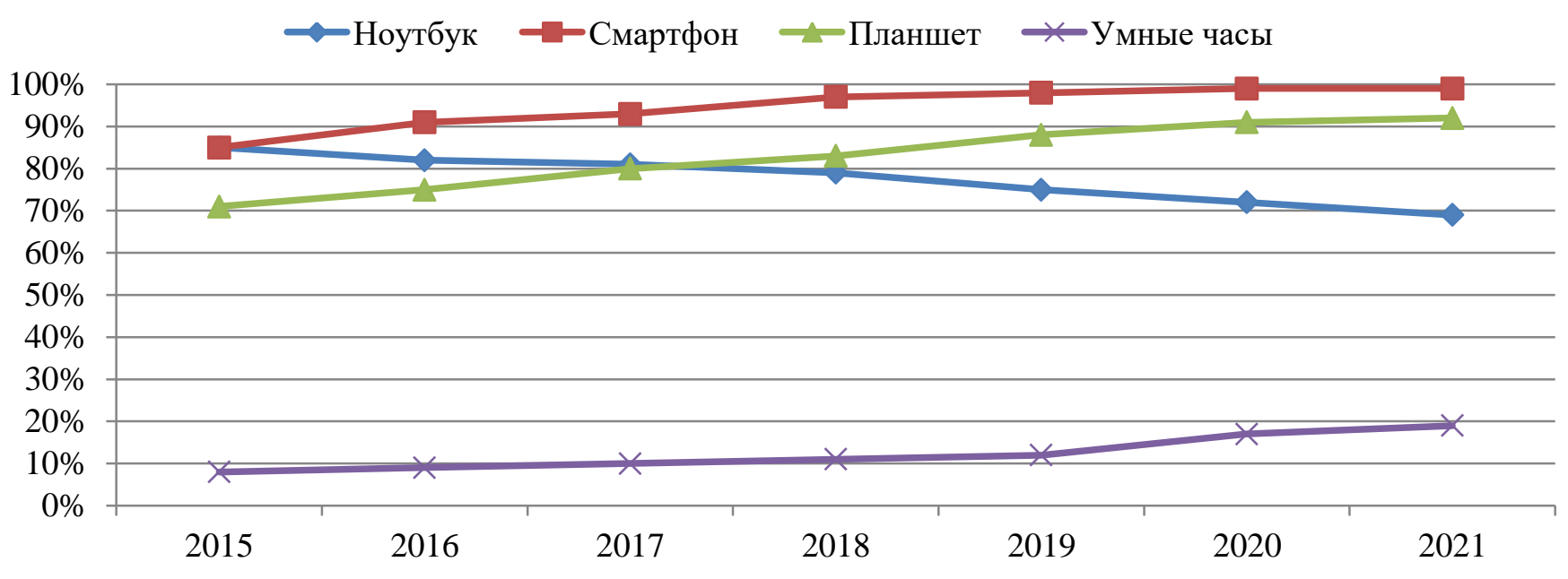

\section{Рис. 1 Результаты опроса компании Atmosphere Research пассажиров в США об используемых для покупки авиационных услуг гаджетах}

К 2021 году инновации потребуют от предприятий воздушного транспорта систем, основанных на новейших технологиях, либо совместимых с ними.

Развитие мобильных технологий привело к необходимости обеспечения возможности взаимодействия с программным обеспечением распознавания речи. Центральную роль в обеспечении динамичного ценообразования и персонализации будет играть искусственный интеллект.

Технологии постоянно меняются, и для каждого аэропорта прежде всего важно быть связанным со своими пассажирами - прислушиваться к их потребностям и реагировать на то, как аэропорт может помочь сделать опыт пассажиров более легким и приятным. Реальность такова, что большинству аэропортов нужны и веб-сайт, и мобильное приложение. Веб-сайты - отличный способ донести до пассажиров основную информацию об аэропорте, но для донесения текущей и актуальной информации аэропорту необходимо наличие гибкого мобильного приложения.

Сейчас многие крупные аэропорты и авиакомпании мира, такие, как аэропорт Стамбула и авиакомпании Cathay Pacific и Singapore Airlines, уже инвестировали в мобильные приложения, осознавая, что потребительский опыт играет огромную роль в формировании устойчивого имиджа авиапредприятия среди многочисленных конкурентов.

Преимущества создания мобильного приложения для пассажиров заключаются в повышении психологического комфорта пассажиров и возможности работы современем, проведенным пассажирами в зонах аэропорта - предоставление информации о рейсе в приложении позволяет пассажиру не 
терять свое время в ожидании у выхода на посадку или в сомнениях о том, хватит ли ему времени, чтобы добраться до своего выхода на посадку ко времени ее начала.

Также создание мобильного приложения может внести свой вклад в развитие бренда аэропорта. Мобильное приложение в динамике времени и приобретении все более и более обширного круга пользователей может стать рекламной платформой с многими партнерами и спонсорами, что является перспективным направлением развития неавиационной деятельности аэропорта.

Что также может повлиять на увеличение доходов неавиационной деятельности аэропорта, так это работа со свободным временем пассажира в зонах аэропорта во время ожидания задержанного рейса или прибывшего поздно борта - чем больше времени пассажир проведет не у выхода на посадку или у прибытия, тем выше вероятность того, что он принесет аэропорту прибыль в неавиационной деятельности, посещая рестораны, кафе, магазины и бизнес-залы. Как и в любом проекте, хорошая стратегия и надлежащее исполнение будут ключевыми элементами, но надежные маркетинговые усилия не менее важны для постоянного успеха приложения.

Используя преимущества встроенных технологий смартфонов, которые веб-сайт просто не может использовать, мобильное приложение для аэропорта может многое сделать для улучшения обслуживания пассажиров в аэропорту. Это также может помочь увеличить неавиационный доход. Рассмотрим несколько способов, которыми мобильное приложение может помочь получить этот доход, одновременно улучшая опыт в терминале для пассажиров.

Приложения для аэропорта оптимизируют опыт пассажиров - аэропорты - это сложные условия, которые могут вызывать разочарование и стресс. С помощью приложения аэропорта можно автоматически отправлять pushуведомления пассажирам, информируя их об изменениях гейта или самого быстрого пути прохождения предполетного досмотра - снижая нагрузку, экономя время и поддерживая бесперебойное движение по всему терминалу. Пассажиры, которые не испытывают стресса или спешки, могут обратить свое внимание на магазины, рестораны аэропорта и на другие предоставляемые в аэропорту услуги.

Приложения для аэропортов обеспечивают индивидуальную пошаговую навигацию - навигация с помощью смартфона стала основным опытом. Можно представить приложение, обеспечивающее пошаговую навигацию по аэропорту в режиме реального времени с предоставлением времени перемещения до выхода на посадку, обновленной информацию о наличии парковки в аэропорту и времени ожидания на входном и предполетном досмотре. Навигация предлагает еще один способ упростить обслуживание пассажиров, но также 
помогает пассажирам находить привлекательные и приятные взаимодействия с брендом аэропорта. Приложение может помочь пассажирам найти открытую парковку или отличный ресторан, найти магазин электроники или аптеку.

Приложения для аэропортов позволяют проводить рекламные акции в реальном времени - мы все смотрим на витрины магазинов в аэропорту, когда идем через терминал. Что если пассажир получит персональный код купона на свой телефон прямо при входе в книжный магазин? С такими технологиями маячков магазины, лавки, рестораны и другие поставщики могут платить аэропорту за продвижение своего бизнеса. Больше продаж в магазине вместе с дополнительными рекламными сборами в итоге приносят больше доходов для аэропорта.

Приложения для аэропорта могут быть монетизированы - благодаря целевым сегментам аудитории, которые проходят через аэропорт (например, деловые путешественники, отдыхающие семьи и т. д.), реклама в приложениях также может увеличить неавиационный доход. Многие бренды заинтересованы в получении доступа к таким ясным группам целевой аудитории - и были бы рады купить часть приложения для рекламы. Бренды будут платить за продажу рекламного пространства в приложении, так же как за продажу места на рекламных щитах или цифровых вывесках.

Мобильные данные могут улучшить стратегии доходов и операций - по мере того, как пользователи вашего приложения путешествуют через аэропорт и везде, где бы они ни находились, - они несут с собой свои смартфоны или планшеты. Это создает ежедневный цифровой след, который может многое рассказать о том, что они делают, когда, почему и как. Можно использовать эту информацию, чтобы постоянно тестировать и совершенствовать свои стратегии неавиационных доходов, лучше понимать поток трафика в аэропорту, оптимизировать линии безопасности и многое другое. Этот вид контекстных мобильных данных недоступен без мобильного приложения, и в итоге он может сделать стратегии более умными и помочь сделать операции более плавными, что означает больший доход по всему терминалу и развитие клиентоориентированности.

Когда пассажиры чувствуют себя хорошо в аэропортуи когда они чувствуют, что аэропорт является ультрасовременным, хорошо управляемым и инвестирует в благополучие пассажиров, - это создает и поддерживает сильный бренд. Это помогает привлекать соглашения и другие деловые поездки и повышает лояльность среди путешественников. И это делает аэропорт местом, где люди хотят тратить свое время и деньги, а не просто местом, которое они должны проехать по пути в другой пункт назначения.

Мобильные приложения сейчас являются важными элементами обслуживания, которого ожидают пассажиры. Учитывая потенциал роста для 
аэропортов, чтобы связаться с пассажирами в режиме реального времени, аэропорт входит в это конкурентное пространство скорее раньше, чем позже.

\section{Список литературы}

1. Тюняев А.Е. Неавиационная деятельность и ее развитие в российских аэропортах. [Электронный ресурс]. - Режим доступа: https://cyberleninka.ru/ article/n/neaviatsionnaya-deyatelnost-i-ee-razvitie-v-rossiyskih-aeroportah/viewer, свободный, (дата обращения: 20.04.2020);

2. Отчет ACI о неавиационной деятельности в 2017 году. [Электронный pecypc]. - Режим доступа: https://www.internationalairportreview.com/news/83 873/report-non-aeronautical-revenues/, свободный, (дата обращения: 20.04.2020)

(c) И. А. Фомина, Д. В. Сливинский, М. И. Шурыгина 